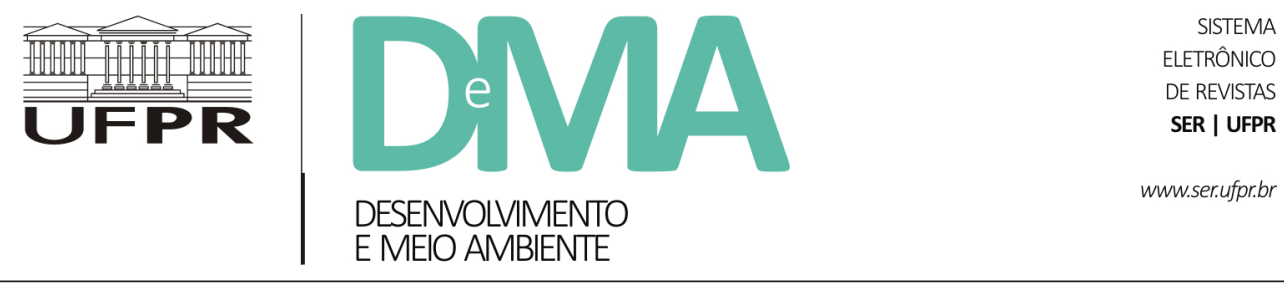

\title{
Impactos socioambientais da suinocultura no oeste catarinense e a iniciativa de implantação de biodigestores pelo Projeto Alto Uruguai
}

\section{Social and Environmental Impacts of Pig Farming in the Western Region of Santa Catarina and the Initiative of Digesters Deployment by the "Alto Uruguai" Project}

\author{
Silvana Teresinha WINCKLER ${ }^{1 *}$, Arlene RENK ${ }^{1}$, Lizete LESSA ${ }^{1}$ \\ ${ }^{1}$ Universidade Comunitária da Região de Chapecó (Unochapecó), Chapecó, SC, Brasil. \\ *E-mail de contato: silvanaw@unochapeco.edu.br
}

Artigo recebido em 4 de agosto de 2016, versão final aceita em 22 de junho de 2017.

RESUMO: $\quad$ O trabalho tem como objetivo discutir impactos socioambientais decorrentes da produção suinícola na região oeste de Santa Catarina. Nesse contexto, prioriza-se a problemática originada pela gestão inadequada dos dejetos de suínos: fonte de poluição do solo, água e ar e origem de inúmeros desconfortos para a população rural, como a incidência de mosquitos e o mau cheiro. Sobressai, no entanto, nessa problemática, a fiscalização ambiental, que ameaça a continuidade das atividades nesse setor por inadequação às normas do licenciamento ambiental. De outra parte, destaca-se o potencial de utilização desse resíduo como fonte energética, mediante a produção de biogás. O Projeto Alto Uruguai é pioneiro na instalação de biodigestores em propriedades rurais da região, criando perspectivas de saneamento ambiental e de aproveitamento econômico dos resíduos da suinocultura. No entanto, esbarra em dificuldades tecnológicas, de gestão e também legais, que serão discutidas no texto. Palavras-chave: conflitos socioambientais; energias alternativas; produção distribuída da energia; TAC da suinocultura

ABSTRACT: This work aims to discuss the social and environmental impacts of pig farming in the western region of Santa Catarina. In this context, we focus on the problems caused by inadequate management of swine waste which may be the source of soil, water and air pollution, and lead to much discomfort to the rural population, due to the increase in incidence of mosquitoes and stench. However, among all issues, the environmental inspection 
stands out, since it threatens the continuity of activities in this sector by the inadequacy of the environmental licensing standards. On the other hand, there is great potential for using this waste as an energy source, through the production of biogas. The "Alto Uruguai" project pioneers in installation of biodigesters in rural properties in the region, which in turn improves perspectives for environmental sanitation and economic recovery of waste from pig farming. Nevertheless, it stumbles when facing obstacles regarding technology, management, and legal difficulties, all of which are discussed in this study.

Keywords: social and environmental conflicts; alternative energies; distributed generation of energy; swine farming's TAC.

\section{Introdução}

Os conflitos socioambientais são inerentes aos processos produtivos que têm forte inserção local e que são dependentes de recursos naturais, como solo e água, e de recursos humanos concentrados em um segmento populacional, como é o campesinato. $\mathrm{O}$ predomínio de uma atividade econômica marca a região e produz impactos ambientais e socioculturais relevantes. Neste cenário situamos o problema da gestão inadequada dos resíduos da suinocultura, um desafio que se apresenta aos agricultores familiares integrados ao setor agroindustrial do segmento frigorífico e, de igual modo, ao segmento empresarial e ao poder público da região oeste de Santa Catarina, por ser esta uma atividade central na economia regional.

Além de apresentar a problemática ambiental ensejada pela atividade suinícola, tem-se como objetivo, neste trabalho, descrever as ações desencadeadas a partir da iniciativa do Ministério Público estadual de elaborar termos de compromisso de ajustamento de conduta envolvendo diversos atores públicos e privados com inserção nesse segmento produtivo. Dentre as ações, merecem destaque as adequações ambientais dos estabelecimentos produtores de suínos e o Projeto Alto Uruguai, que viabiliza a instalação de biodigestores nas unida- des familiares de produção integrada como medida de saneamento ambiental e de potencial econômico, tendo em vista a minoração da poluição e a produção de adubo orgânico e de biogás para consumo na propriedade.

Alguns aspectos da historiografia contribuíram para a conformação dos elementos identitários da região do estudo, como se verá adiante.

\section{A suinocultura no oeste de Santa Catarina}

A ocupação territorial da região oeste de Santa Catarina ensejou conflitos, alguns dos quais ainda são visíveis nos dias atuais. A população autóctone do oeste de Santa Catarina, majoritariamente indígenas das etnias kaingang e guarani, conviveu durante décadas com a população cabocla nela instalada e que, anos antes, encontrava ocupação nas "terras de criar" e na lida com as tropas de gado trazidas do Rio Grande do Sul e tocadas por terra até o mercado consumidor paulista (Renk, 2006). Em contexto agrário de áreas não demandadas para a agricultura, nas terras de criar, os caboclos dedicavam-se à criação de animais soltos, longe de suas terras de plantar. De acordo com a hierarquização desse segmento populacional, havia aqueles que se dedicavam à criação de suínos soltos no mato, o chamado "por- 
co alçado", alimentado com frutos silvestres. Esse sistema exigia áreas amplas, não concorridas como terras de lavoura (Correa Lobato, 1970).

As presenças indígena e cabocla se viram contrastadas, nas primeiras décadas do século XX, pela chegada dos colonos descendentes de europeus, vindos do Rio Grande do Sul para formar novos núcleos coloniais. A escassez de terras nas "colônias velhas" era motivo suficiente para encorajar a incursão por terras de mata, mais baratas, oferecidas pelas companhias colonizadoras. O mais importante fator de contraste, à parte o aspecto étnico, por si evidente, era a forma de relacionar-se com a terra. A concepção de terra entre colonizador e autóctone apresentava diferenças. Para indígenas e caboclos, a terra não era mercadoria, consideravam-na patrimônio moral. Sua relação com a terra não supunha a formalização legal da posse, nem a escrituração ou a demarcação das glebas - hábito que conduziu essa população a um estado de vulnerabilidade (Werlang, 2006; Renk, 2006).

Em contraponto a esse cenário, o processo colonial consistiu fundamentalmente na formalização do direito de propriedade dos colonos sul-rio-grandenses sobre as colônias novas no estado catarinense. Implicou a demarcação, a "limpeza" (derrubada da mata e retirada de eventuais ocupantes, transformados em intrusos), a construção de cerca e o cultivo, fatores que evidenciavam a posse, elemento de exteriorização do domínio legal sobre a terra.

As formas tradicionais de uso da terra por indígenas e caboclos não tinham, naquela época, qualquer valor legal, de modo que esses sujeitos foram expulsos dos lugares que até então ocupavam, envoltos nas sombras da invisibilidade jurídica e da marginalidade social.
Com a Lei de Terras (Lei n. 601/1850), na região que hoje designamos como oeste de Santa Catarina, os ocupantes de terras tiveram prazo para registrar suas possessões. Assegurava-se, com essa medida, o direito sobre as áreas ocupadas. Quem registrou tornou-se efetivamente dono; quem não registrou ficou definitivamente excluído da possibilidade de exercer direitos em relação ao seu lugar de moradia e de trabalho. Permanecer na terra passou a ser uma questão de favor ou benevolência do legítimo detentor, isto é, do proprietário (Renk, 2006). O processo se agudiza com a transferência de glebas de terra às companhias colonizadoras sul-riograndenses instaladas após a Guerra do Contestado (1912-1916), com vistas ao empreendimento colonizador. Essas companhias recrutam os agricultores do Estado do Rio Grande do Sul, que, em estratégia de reprodução social camponesa, migram buscando lotes coloniais em condições favoráveis.

As colônias novas do oeste de Santa Catarina foram organizadas em pequenas propriedades, em torno de 24 hectares, hoje consideradas minifúndios pela legislação ambiental, a exemplo do Código Florestal Brasileiro (Brasil, 2012). O grande número de filhos por casal assegurava a abundância da mão de obra familiar, logo traduzida em incremento da produção agrícola. A criação de animais, especialmente aves e suínos, foi uma das consequências do modelo de organização das unidades familiares, capazes de produzir alimentos para a subsistência e de gerar excedentes que poderiam ser comercializados. Formou-se um mercado de trocas encarregado de prover as famílias de gêneros não produzidos para autoconsumo e de dar destinação à produção excedente, que era enviada para mercados consumidores mais distantes 
(Renk, 2006). Testa et al. (1996) descrevem essa forma de organização da produção como "agricultura subordinada à suinocultura".

Nesse sistema, intensificou-se a produção de suínos, que eram conduzidos vivos a outras regiões do País ou vendidos como carne e banha aos consumidores locais. Não tardou que empresários visualizassem a oportunidade de ali instalar frigoríficos que potencializassem a produção e o comércio de banha, carne e derivados de carne suína (Espíndola, 1999; Bavaresco, 2005).

Entre as décadas de 1940 e 1960, inúmeros frigoríficos se instalaram na região oeste de Santa Catarina. A partir dos anos 1970, teve início a industrialização em grande escala, de modo que a região se converteu na principal produtora e exportadora de carne suína e de produtos dela derivados. Instituiu-se o modelo de integração vertical na suinocultura, mediante o qual as unidades familiares de produção ficavam vinculadas por contrato a uma agroindústria, da qual recebiam as matrizes de aves e suínos e a assistência técnica, com o compromisso de entregar toda a produção ao final de um prazo estipulado. A disponibilidade de mão de obra, água e alimento (sobretudo o milho) assegurava a produtividade e a rentabilidade aos integrados.

Esse modelo organizacional é conhecido no setor como integração, no qual o suinocultor se insere na cadeia produtiva vinculado a uma agroindústria de abate e processamento que, geralmente, também coordena os elos a montante da produção primária, sobretudo na fabricação de ração. A integração predomina na suinocultura da região Sul do País, mas cresce nas demais regiões acompanhando a expansão geográfica das agroindústrias líderes. Entretanto, há uma multiplicidade de formas organizacionais coexistindo, com um expressivo número de suinocultores não integrados, denominados no setor de independentes.
(Miele \& Waquil, 2007, p. 818).

A partir da década de 1980, estudos (Testa et al., 1999; Bavaresco, 2005) apontam que houve redução na produção agrícola e também na mão de obra familiar. Em sentido oposto, registrou-se crescimento no número de suínos produzidos em cada unidade familiar, o que denota o fenômeno da concentração da suinocultura. As empresas integradoras começaram a fornecer o alimento (ração) para os plantéis, as horas diárias de trabalho dedicadas ao cuidado dos animais sofreram um incremento e os ganhos financeiros diminuíram. A atividade suinícola ganhou escala e passou a demandar mais trabalho da família, sem assegurar o correspondente aumento na disponibilidade de mão de obra. Intensifica-se, portanto, a autoexploração laboral.

As vantagens que motivaram a adesão de cerca de 4 mil famílias ao modelo de suinocultura integrada à agroindústria - quais fossem, a capacidade de produzir proteína animal em curto prazo, utilizando mão de obra familiar e aproveitando a produção agrícola da unidade familiar de produção (Testa et al., 1996) - pouco a pouco arrefeceram. Permanecer na atividade passou a ser um desafio diário, requerendo disponibilidade de capital financeiro para investimentos em infraestrutura e novas tecnologias.

Ao lado da problemática socioeconômica, já então percebida, outra questão começou a chamar a atenção dos pesquisadores e da sociedade regional nos anos 1990: a pressão ambiental exercida pela produção de suínos sobre os recursos naturais. $\mathrm{O}$ incremento na produtividade foi assegurado, por um lado, pela melhoria genética dos animais e, por outro, pelo aumento quantitativo nos plantéis. As áreas de cultivo, de outra parte, foram progressivamente 
reduzidas, de modo que os dejetos oriundos da suinocultura acabaram se acumulando em extensões de terras insuficientes para assegurar a ciclagem de nutrientes. A sobrecarga destes no solo, como se sabe, leva à contaminação ambiental. Solo, água e ar apresentam sobrecarga de poluição, mas a consequência mais preocupante é a contaminação das águas superficiais e subterrâneas. Ressalte-se que, num momento inicial, por parte do serviço de extensão rural, houve orientação de que as pocilgas se situassem próximas a cursos d'água para facilitar a limpeza dos estabelecimentos. A água levaria consigo os dejetos. Num momento posterior, houve a proibição da construção de pocilgas em áreas próximas a rios e fontes, ante o risco de contaminação (Santa Catarina, 1985).

O relatório final de Avaliação do Projeto Microbacias - Monitoramento da Qualidade da Água, produzido pelo Instituto Cepa/SC, em 1999, apresentava o cenário de contaminação dos mananciais hídricos no meio rural do estado:

A poluição da água por coliformes fecais nas áreas rurais de Santa Catarina está associada principalmente à criação de suínos, em especial na região Oeste, onde cerca de $80 \%$ do rebanho estadual está concentrado numa área aproximada de 30.000 quilômetros quadrados. A maior parte deste volume de dejetos é armazenada, não recebe tratamento adequado e é aplicada no solo como fertilizante. Às vezes, os dejetos são despejados diretamente em córregos e riachos. Em muitas propriedades, o volume gerado é superior à capacidade de armazenamento, não permitindo que o dejeto permaneça o tempo necessário para sua estabilização. Muitas dessas propriedades não possuem área agricultável para receber tal volume. (Santa Catarina, 1999, p. 9)
Dados da Pesquisa Pecuária Municiapal de 2003 revelaram que Santa Catarina possuía, naquele ano, plantel de 5,4 milhões de suínos, que produziam volume diário de 40 mil metros cúbicos de dejetos. Esse volume era lançado ao ambiente sem qualquer tipo de tratamento. Na região oeste do estado, onde a atividade está concentrada, a estimativa era de produção diária de 30 mil metros cúbicos de dejetos (Miranda et al., 2012).

Pesquisadores vinculados ao Projeto Rede Aquífero Guarani/Serra Geral vêm manifestando preocupações com os riscos de contaminação das águas desses aquíferos, que recobrem cerca de $50 \%$ do subsolo do Estado de Santa Catarina e representam uma das maiores reservas de água potável do planeta. Isso porque em $60 \%$ dos 316 poços de uso público analisados nas cidades abastecidas pelas bacias dos rios Jacutinga, do Peixe e Chapecó, na região oeste, foram encontrados coliformes fecais. O coordenador da rede, professor Luiz Fernando Scheibe (UFSC), alerta que a má gestão dos esgotos urbanos e dos dejetos da atividade agropecuária poderá, de fato, levar à contaminação das águas subterrâneas (Diário Catarinense, 2013).

As denúncias levadas ao Ministério Público do estado acerca de incidentes (intencionais ou não) de derramamento de dejetos em rios e córregos tornaram-se recorrentes. As inadequações ambientais, constatadas na maior parte das unidades familiares de produção, passaram a dificultar o licenciamento ambiental da atividade suinícola, acrescentando ao quadro, já complexo e de difícil solução, a questão da regulação ambiental das atividades de risco. 
O Ministério Público de Santa Catarina buscou uma solução negociada para o problema, envolvendo diversos atores ${ }^{1}$. Fazendo uso da Lei da Ação Civil Pública (Lei n. 7.347/1985), propôs a assinatura de um Termo de Compromisso de Ajustamento de Conduta (TAC), no qual as partes admitem a responsabilidade em relação ao problema e se comprometem a adotar medidas de mitigação.

Dentre as medidas preconizadas, constam: recuperação da mata ciliar nas áreas de preservação permanente em faixas proporcionais à largura dos cursos d'água, realização de eventos para orientar os produtores suinícolas sobre o conteúdo do TAC, licenciamento ambiental da atividade na Fatma, elaboração de projetos técnicos para adequação ambiental das propriedades suinícolas, assessoria técnica aos produtores suinícolas inseridos no Programa Nacional do Meio Ambiente $\mathrm{II}^{2}$, assessoria na execução do projeto técnico para manejo adequado dos dejetos e economia de recursos hídricos, insumos destinados à implementação dos projetos técnicos de sistemas de armazenamento de dejetos nas propriedades suinícolas, entre outras.

O TAC foi uma condição imposta pelo Ministério Público para a continuidade das atividades suinícolas na região, posto que a maior parte das unidades familiares de produção não possuía condições de obter licença ambiental de operação. $\mathrm{O}$
TAC, assinado em 29 de julho de 2004, teve como abrangência territorial a região da Associação dos Municípios do Alto Uruguai Catarinense (Amauc), que compreende 16 municípios e tem a maior concentração de suínos do País. O documento foi apresentado em audiência pública realizada no dia 31 de outubro de 2001, na sede da Embrapa, em Concórdia.

$\mathrm{Na}$ audiência pública, foi convencionado que o Consórcio Lambari coordenaria a atividade de diagnóstico das unidades de produção (cerca de 4 mil propriedades), abrangendo $100 \%$ das unidades integradas às agroindústrias. Era necessário conhecer os dados sobre a atividade: o número de animais em criação, as formas de armazenamento dos dejetos e de distribuição no solo, a quantidade de áreas disponíveis para dispersão, a localização das esterqueiras e as distâncias destas em relação às estradas, cursos d'água e moradias. Os primeiros levantamentos revelaram que mais de $90 \%$ das unidades estavam funcionando sem licença ambiental. O mais preocupante era que $78 \%$ delas não estavam adequadas à legislação ambiental por um ou mais fatores: $64 \%$ por escassez de área, $71 \%$ por déficit na capacidade de armazenamento dos dejetos e $71 \%$ por localização inadequada das instalações (Embrapa Suínos e Aves, 2003 apud Miranda et al., 2012). Nesse contexto, ganhou protagonismo o

\footnotetext{
${ }^{1}$ Além do Ministério Público de Santa Catarina, assinaram o TAC a Secretaria de Estado do Desenvolvimento Social, Urbano e Meio Ambiente, a Secretário de Estado da Agricultura e Política Rural, o Comando Geral Companhia de Polícia Militar de Proteção Ambiental, a Associação Catarinense de Criadores de Suínos, o Sindicato da Indústria da Carne e Derivados de SC (Sindicarne), a Fundação do Meio Ambiente (Fatma), a Embrapa Aves e Suínos, a Empresa de Pesquisa Agropecuária e Extensão Rural de Santa Catarina (Epagri) e a Companhia Catarinense de Águas e Saneamento (Casan).

${ }^{2}$ O PNMA II, objeto de acordo de empréstimo entre o governo brasileiro e o Banco Mundial ( $\mathrm{n}^{\circ}$ 4524-BR), está estruturado em dois componentes: gestão integrada de ativos ambientais e desenvolvimento institucional com os subcomponentes de licenciamento ambiental, monitoramento da qualidade da água e gerenciamento costeiro. No caso específico, o objetivo consistiu em desenvolver atividades de recuperação ambiental decorrentes dos despejos de dejetos suínos nas bacias dos rios Fragoso e Coruja/Bonito, com a realização do licenciamento e do monitoramento ambiental (Brasil/MMA, 2015).
} 
Comitê Regional da Suinocultura da Região da Amauc, formado por representantes dos diversos setores ligados direta ou indiretamente à cadeia produtiva da suinocultura. Dentre as atribuições do comitê, está a de viabilizar financiamentos para a adoção de medidas de adequação da suinocultura à legislação sanitária e ambiental.

Desde a assinatura do TAC, realizaram-se seminários anuais de avaliação do processo. Dentre os resultados alcançados, merecem destaque a adequação dos sistemas de armazenamento de dejetos na totalidade das unidades de produção e a formação de uma rede de monitoramento da qualidade das águas superficiais (Miranda \& Palhares, 2011).

Circunstâncias similares àquelas encontradas na região de Concórdia ensejaram a iniciativa do Ministério Público de Santa Catarina de propor a formulação de TAC para as regiões da Associação dos Municípios do Alto Irani (Amai), Associação dos Municípios do Oeste de Santa Catarina (Amosc) e Associação dos Municípios do Noroeste de Santa Catarina (Amnoroeste). A assinatura do TAC ocorreu em 9 de dezembro de 2008, na cidade de Chapecó. Em linhas gerais, as obrigações assumidas pelas partes reproduzem aquelas anteriormente mencionadas. Com relação a esse segundo TAC, ainda não se dispõe de avaliações dos resultados obtidos, mas um deles é evidente: a continuidade da atividade suinícola, assegurada pelo licenciamento ambiental das unidades produtoras.

\section{Biodigestores, biogás e aproveitamento econômico}

A biodigestão anaeróbia é uma das formas naturais de se obter o hidrocarboneto metano. Em- bora a biodigestão anaeróbia tenha sido aplicada desde o começo do século para o tratamento de efluentes residenciais, a grande evolução desse processo deu-se na Índia, a partir de 1939, quando o Instituto Indiano de Pesquisa Agrícola, em Kanpur, desenvolveu a primeira usina de gás de esterco, em Bengali Gobar, dando origem, em 1950, ao Gobar Gas Institute. Houve grande difusão do biodigestor como forma de tratar o esterco e obter combustível sem perder o efeito fertilizante. Esse trabalho ficou conhecido como "modelo indiano" e possibilitou a construção de quase meio milhão de unidades biodigestoras no interior da Índia (Nogueira, 1986).

No Brasil, o interesse pela energia gerada pelos biodigestores data do início da década de 1970, no contexto da crise do petróleo. Houve, então, necessidade de procurar outras fontes de energia, estimulando a pesquisa e o consequente uso dessa tecnologia (Nogueira, 1992; Esperancini et al., 2007; Rizzoni et al., 2012).

A agroenergia está consolidada como atividade econômica oficialmente reconhecida e estimulada. É um novo negócio, uma nova fonte de renda para as famílias do campo; outro produto, independente do tradicional, que gera receita própria, regulado por um mercado com prazo, preço e firmeza de contratação - contratos de longo prazo -, envolvendo concessionárias distribuidoras reguladas publicamente.

$\mathrm{O}$ avanço da agroenergia tem peso significativo na matriz energética brasileira e constitui uma nova disponibilidade de energia, com base em fontes renováveis. Cria-se uma nova dimensão para o setor rural, que passa a ter a possibilidade de gerar energia. Essa energia pode ser destinada ao consumo próprio, à alimentação da propriedade rural geradora (autogeração) ou à venda direta ao 
consumidor, o que liberaria energia do Sistema Interligado Nacional (SIN) para outras demandas da sociedade (Brasil/MME, 2015).

A geração de energia pode levar a propriedade rural à autossuficiência e à autonomia energética, não descartando a possibilidade da comercialização do excedente. Além de abastecer as instalações da propriedade, a energia gerada pelo biodigestor pode abastecer veículos que servem para movimentar cargas agrícolas, desde que estes tenham motores elétricos movidos a baterias, reduzindo, assim, a necessidade da utilização de combustíveis fósseis. No entanto, os custos das tecnologias ainda são um obstáculo em termos de acessibilidade.

De modo geral, a biomassa residual pode surpreender pelos impactos positivos de sustentabilidade direta e indireta que é capaz de produzir, seja regionalmente, seja em territórios distantes, mediante a conexão ao SIN. Com tecnologias acessíveis aos produtores rurais, treinamentos e capacitações específicas, poderá representar importante fonte de energia renovável para a estrutura agrícola brasileira, além de novos postos de trabalho no espaço rural.

Outra fonte de renda associada ao emprego dos biodigestores é a produção do biofertilizante, produto final da digestão anaeróbia, consistente num efluente rico em nutrientes orgânicos e inorgânicos. Algumas vantagens do uso do biofertilizante são o aumento da capacidade de retenção da umidade no solo; a melhoria da estrutura e da textura do solo, facilitando o desenvolvimento das raízes; a economia feita em relação ao adubo industrializado e a insumos agrícolas; a diminuição do odor exalado pelas matérias orgânicas em decomposição; a redução de danos ao meio ambiente; o aumento da qualidade de vida, da saúde do produtor rural e dos consumidores; e o incremento na renda do produtor rural com a sua comercialização (Nogueira, 1986).

\section{Projeto Alto Uruguai}

O Projeto Alto Uruguai - Cidadania, Energia e Meio Ambiente é um projeto-piloto de caráter nacional. Trata-se de uma parceria entre o Movimento dos Atingidos por Barragens (MAB), a Eletrobras, a Eletrosul, a Universidade Comunitária da Região de Chapecó (Unochapecó) e 29 municípios da região do Alto Uruguai ${ }^{3}$, com a finalidade de viabilizar o aproveitamento energético dos resíduos de suínos, como forma de diminuir o impacto ambiental causado pela principal atividade pecuária do oeste do Rio Grande do Sul e de Santa Catarina.

A ideia do projeto foi lançada quando da realização do Seminário Energia e Desenvolvimento, em 2003. O seminário foi iniciativa do MAB, da Prefeitura Municipal de Chapecó e da Unochapecó e permitiu aprofundar o debate acerca das relações entre o desenvolvimento regional e as formas de produção e consumo de energia no Alto Uruguai (Baron, 2012).

Em 5 de maio de 2004, na cidade de Chapecó (SC), aconteceu o lançamento do Projeto Alto Uruguai, na presença de mais de 600 lideranças oriundas dos referidos 29 municípios da região oeste do Rio

\footnotetext{
${ }^{3}$ Os municípios que participam do projeto são, no Rio Grande do Sul: Alpestre, Caiçara, Erval Grande, Faxinalzinho, Itatiba do Sul, Nonoai, Iraí, Vicente Dutra, Pinheirinho do Vale e Rio dos Índios; em Santa Catarina: Itapiranga, São Domingos, Seara, Concórdia, Mondaí, Riqueza, Caibi, Flor do Sertão, Caxambu do Sul, Ipuaçu, Chapecó, São Carlos, Guatambu, Paial, Xavantina, Quilombo, Águas de Chapecó, São João do Oeste e Palmitos.
} 
Grande do Sul e de Santa Catarina. Nesse mesmo dia, foi assinado o termo de compromisso. Em maio de 2005, foi assinado convênio entre a Eletrobras e a Eletrosul para dar início ao projeto.

A coordenação do Projeto Alto Uruguai, em sua primeira fase, ficou a cargo da Eletrobras, da Eletrosul, do MAB, da Unochapecó e do Instituto de Pesquisa e Planejamento Urbano e Regional (IPPUR/UFRJ), contando com o apoio dos $29 \mathrm{mu}-$ nicípios da região oeste dos dois estados.

A meta do projeto é converter a região oeste dos estados do Rio Grande do Sul e de Santa Catarina, que está situada na bacia hidrográfica do Alto Uruguai, em modelo de produção e consumo. O projeto foi desenvolvido com base em três eixos: a conservação de energia e sua utilização de forma racional, de modo a evitar o desperdício; a produção alternativa de energia, com ênfase na conservação do meio ambiente; e a inclusão energética, pelo Programa Luz para Todos, de iniciativa do governo federal. Os municípios beneficiados margeiam o rio Uruguai e possuem características econômicas, sociais e ambientais comuns (Dal Magro et al., 2007; Projeto Alto Uruguai, 2015).

Respeitadas as particularidades, os municípios foram avaliados de modo a permitir que as propriedades onde seriam instalados os biodigestores estivessem de acordo com os parâmetros idealizados pelo projeto. Assim, elas deveriam preencher os requisitos necessários em cada uma das variáveis apresentadas: ambientais, sociais, econômicas, estruturais, de gestão e de controle de campo. A primeira fase estabeleceu critérios de avaliação para a escolha das propriedades rurais que iriam receber o projeto-piloto de colocação de biodigestores para, inicialmente, fazer apenas a queima do gás metano.

O projeto é patrocinado pelas empresas Eletro- bras e Eletrosul: coube à Eletrobras o aporte do montante de R\$ 3,6 milhões (três milhões e seiscentos mil reais), correspondentes a 95,24\% do valor total do convênio; a Eletrosul investiu R \$ 180 mil (cento e oitenta mil reais), correspondentes aos outros 4,76\% do valor conveniado.

Em entrevista, o sociólogo Sadi Baron, secretário executivo da primeira fase do projeto, informa que, para dimensionar o resultado dessa fase, foi aplicado aos produtores que possuem biodigestor um questionário para que relatassem sua percepção após a instalação do equipamento. Os resultados relatados foram a sensível diminuição do odor dos resíduos, que antes eram lançados em rios e nas áreas de cultivo, a diminuição de moscas na propriedade e a consequente melhoria na qualidade ambiental. Outro ponto mencionado pelos proprietários foi a produção do biofertilizante. Os produtores constataram os benefícios causados ao solo justamente pelas características físico-químicas do fertilizante natural. Segundo dizem, o biofertilizante tem qualidade superior aos encontrados no mercado e, apesar de ser um subproduto dos resíduos de suínos, o odor não é tão ruim quanto o destes - está sendo utilizado próximo às residências, em pomares e jardins.

Por outro lado, o biofertilizante tem muita água, o que dificulta o transporte para venda. Os entrevistados indicam a necessidade de destinação alternativa para o excesso de produção de biofertilizante, aquele que não pode ser totalmente aproveitado na propriedade produtora.

A segunda fase do projeto já está em andamento e contempla a instalação de uma central de geração de energia alimentada por 12 biodigestores, instalados em propriedades distintas - situadas no município de Itapiranga (SC) - e interligados por 
um gasoduto (Brasil, 2013). O cronograma do projeto está atrasado por problemas de financiamento.

\section{Desafios tecnológicos e jurídicos para a comercialização da energia}

A percepção sobre o que pode ou não ser um recurso para geração de energia se modifica e evolui em consonância com a disponibilidade de alternativas tecnológicas. O Brasil tem necessidade de diversificar a matriz energética para assegurar o abastecimento residencial e industrial e elidir a dependência dos combustíveis fósseis e da hidroeletricidade. Esta, apesar de ser referenciada como uma energia limpa, não está isenta de críticas, haja vista os impactos socioambientais provocados pelas barragens (Magalhães Santos, 2007; Zhouri, 2012; Dal Magro et al., 2015). Apesar disso, durante muito tempo, não se teve no País uma política pública voltada ao desenvolvimento de fontes alternativas de energia, que contrastassem com as fontes dominantes no cenário energético. O Programa de Incentivo às Fontes Alternativas de Energia Elétrica (Proinfa) foi instituído pelo Decreto n. 5.025, de 2004, com o objetivo de aumentar a participação da energia elétrica proveniente de fonte eólica, biomassa e pequenas centrais hidrelétricas no SIN (Brasil, 2015).

Em Santa Catarina, a Granja São Roque é referência no uso de biodigestores para geração de energia utilizando dejetos de suínos. A granja, localizada nas proximidades do município de Videira, na região meio-oeste, desenvolve um projeto-piloto desde 2003. A propriedade possui, aproximadamente, 47 mil suínos e gera, em 16 horas diárias, o equivalente a $200 \mathrm{~kW}$ mensais. A energia produzida é destinada a suprir o próprio consumo, o da fábrica de rações e o das atividades de piscicultura. A granja produz também o adubo orgânico. Ressalta-se que os dois geradores lá utilizados foram adquiridos com recursos do proprietário e financiamento do Banco Regional de Desenvolvimento do Extremo Sul (BRDE). O excedente de energia era vendido às Centrais Elétricas de Santa Catarina S.A. (Celesc) por meio de contrato de compra e venda. Em 2011, a granja obteve autorização do Operador Nacional do Sistema Elétrico (ONS) ${ }^{4}$ para realizar, de fato, a geração distribuída, conectando-se à rede de distribuição da Celesc (Granja São Roque, 2016).

No oeste do Paraná, a Granja Colombari produz energia para o consumo próprio e vende o excedente para a Companhia Paranaense de Energia (Copel), concessionária de distribuição do Paraná. Em 2009, a energia gerada proporcionava um ganho anual de aproximadamente $\mathrm{R} \$ 6$ mil (seis mil reais), sendo que o biodigestor funcionava 12 horas por dia, seis dias por semana, produzindo 103,7 MWh. Destaca-se que $60 \%$ da energia gerada são utilizados para consumo próprio e $40 \%$ são vendidos à Copel. De acordo com o proprietário da granja, o autoabastecimento gerou "aumento da rentabilidade da propriedade, já que permitiu atender ao crescimento da demanda de energia resultante da ampliação de sua fábrica de rações” (Bley Jr., 2009, p. 98).

\footnotetext{
${ }^{4}$ O Operador Nacional do Sistema Elétrico (ONS) é o órgão responsável pela coordenação e controle da operação das instalações de geração e transmissão de energia elétrica no Sistema Interligado Nacional (SIN), sob fiscalização e regulação da Agência Nacional de Energia Elétrica (ANEEL, 2016).
} 
Há também a experiência realizada no município paranaense de Entre Rios do Oeste, que poderá ser o primeiro no Brasil a ter autossuficiência energética proveniente da geração distribuída de biogás produzido a partir de dejetos de suínos e de esgoto (Wurmeister, 2013).

Dentre os casos de sucesso na utilização de biogás para a geração de energia, o exemplo que mais se aproxima da realidade encontrada no oeste de Santa Catarina é o Condomínio de Agroenergia para Agricultura Familiar da Microbacia do Rio Ajuricaba. Esse projeto vem sendo desenvolvido por Itaipu desde 2009, em parceria com o Instituto Paranaense de Assistência Técnica e Extensão Rural (Emater/PR), a Companhia Paranaense de Energia (Copel), a Prefeitura Municipal de Marechal Cândido Rondon, a Embrapa, o Movimento Nacional dos Pequenos Agricultores (MPA), o Instituto de Tecnologia Aplicada e Inovação (ITAI) e a Fundação Parque Tecnológico Itaipu (FPTI). (Boas práticas para o desenvolvimento sustentável, s/d).

O projeto teve como objetivo a implantação de uma proposta viável para a agroenergia na agricultura familiar, de modo a possibilitar seu desenvolvimento econômico, ambiental, social e energético. Assim, previu a instalação de 34 biodigestores e $22 \mathrm{~km}$ de gasodutos ligados a uma microcentral termelétrica, que se reverte em vantagem econômica para os produtores. Estimou-se que o projeto possa garantir cerca de R\$270 mil anuais aos produtores rurais com a produção de energia térmica, elétrica e veicular, além de biofertilizantes (Itaipu Binacional, 2010).

Em razão das iniciativas de aproveitamento energético das fontes de energia renováveis é que o Estado do Paraná aprovou a Lei n. 17.188, de 13 de junho de 2012, que institui a Polícia Estadual de
Geração Distribuída com Energias Renováveis. Essa lei deixa clara a intenção de incentivar o aproveitamento energético do biogás produzido no meio rural quando assegura que os organismos de pesquisa e extensão rurais, públicos e privados, receberão incentivos para prestar serviços ao desenvolvimento e à inovação na produção e no uso da geração distribuída com energias renováveis em empreendimentos de pequeno porte, a fim de descentralizar o sistema de geração e promover, em escalas industrial e agropecuária viáveis, as tecnologias e os processos que gerem esse tipo de energia.

A lei afiança que as concessionárias locais de distribuição serão estimuladas a participar desse esforço de incentivo à compra de energia proveniente dos dejetos de animais confinados. Embora haja, no País, diversos projetos em andamento e execução de utilização da biomassa como fonte de energia elétrica, ainda é tímida a representatividade do uso de biogás proveniente de dejetos de animais no montante de usinas de biomassa cadastradas na Aneel. Há, atualmente, 503 delas: 390 são de bagaço de cana-de-açúcar; 47, de resíduos de madeira; 17, de licor negro; 12, de biomassa de resíduos de animais; 10, de casca de arroz; 10, de biogás oriundo de resíduos urbanos; 8 , de gás de alto-forno; 6 , de carvão vegetal; 3, de capim-elefante (ANEEL, 2016).

A Aurora Alimentos, de Chapecó, é um exemplo de empresa agroindustrial que aproveita os dejetos de suínos na produção de biogás. São produzidos 20 toneladas de gás por mês, o que representa $70 \%$ do consumo da unidade. Os biodigestores transformam os resíduos em gás, que é utilizado na chamuscagem dos suínos no frigorífico. O gás produzido pelos dejetos de 5 mil animais é canalizado e levado à unidade frigorífica situada no bairro Efapi, que abate 4,5 mil suínos por dia. 
A conversão do metano em energia pode ocorrer de duas formas: por meio de motores de combustão interna, que transformam a energia proveniente de uma reação química em energia mecânica, e por turbinas a vapor, processo no qual a água é aquecida pela queima do gás e impulsiona a turbina para a geração de energia.

O uso de biodigestores para geração de energia elétrica, além de garantir vantagem econômica para quem gera, favorece a disponibilidade no abastecimento de energia e intensifica a diversificação da matriz energética. A energia produzida na propriedade rural pode ser compensada com a distribuidora local, ou seja, a energia gerada é posta na rede e o produtor obtém um crédito que será utilizado quando não houver geração na propriedade ou houver necessidade maior de consumo do que a capacidade de autogeração.

O investimento para a instalação de biodigestores é relativamente alto para o pequeno produtor e depende da quantidade de animais confinados que a propriedade mantém. O tamanho do plantel existente na propriedade é que vai dimensionar o padrão do biodigestor. Além disso, a geração de energia compreende outros equipamentos, como motores, geradores e tubulações.

\section{Considerações finais}

As fontes renováveis de energia passaram a ter maior relevância no cenário energético brasileiro na última década. O modelo do setor elétrico, expresso no Plano Decenal de Energia, contempla a necessidade de ampliação da matriz energética e a consequente diminuição da dependência dos combustíveis fósseis e das usinas hidrelétricas.
É nítido que o estabelecimento de uma política estadual, nos moldes da implementada pelo vizinho estado do Paraná, poderia servir de incentivo às novas iniciativas no âmbito da geração de energias renováveis em Santa Catarina e, de modo especial, na região oeste, tendo-se em conta o potencial de utilização da biomassa oriunda da suinocultura.

Um fator importante a ser considerado é que a destinação adequada dos resíduos da atividade suinícola é questão vital para o setor agroindustrial de carnes e derivados, à medida que condiciona a obtenção das licenças ambientais pelos produtores. A vigência dos TACs da suinocultura para as regiões de Concórdia e Chapecó permitiu ao setor reorganizar-se em bases mais sustentáveis, desde o ponto de vista ambiental.

De outra parte, a geração de energia a partir do biogás poderá converter-se em importante fonte de renda para os suinocultores, compensando as oscilações nos preços das demais commodities e conferindo estabilidade econômica à atividade.

Um aspecto que deve ser levado em conta em relação à experiência da Granja São Roque, relatada anteriormente, é que, naquele caso, há uma grande concentração de suínos na unidade de produção. A extensão dessa experiência a outras regiões do estado poderá ocasionar a exclusão de famílias da atividade suinícola. A instalação de unidades capazes de produzir em grande escala pressupõe um investimento de alta monta, muito acima das possibilidades dos agricultores familiares do oeste de Santa Catarina. Por essa razão, a consolidação do Projeto Alto Uruguai dependerá do estabelecimento de relações de coparticipação entre produtores integrados às agroindústrias, na forma de associações, condomínios ou mesmo cooperativas.

Outro aspecto a ser considerado é a necessida- 
de de financiamento público para as iniciativas locais de geração distribuída, tendo-se em conta $\mathrm{o}$ alto custo das tecnologias hoje disponíveis. $\mathrm{O}$ Projeto Alto Uruguai é um exemplo de que esse tipo de empreendimento é viável e bem recebido pelos suinocultores, especialmente em razão da melhoria das condições sanitárias e ambientais nas propriedades. A questão do financiamento, no entanto, pode ser um obstáculo quando não houver suporte de políticas públicas.

Percebe-se a necessidade de um marco regulatório específico para a geração e a distribuição do biogás oriundo de dejetos de animais e produzido pelo pequeno produtor rural. Dado que este, geralmente, não tem lastro financeiro para subsidiar a instalação de biodigestores em sua propriedade, é essencial que haja uma contrapartida do poder público. Dessa forma, o marco regulatório para atender o pequeno produtor deverá contemplar um amplo espectro de medidas ambientais, sociais e financeiras. Em outras palavras, o marco regulatório poderá estimular o financiamento da tecnologia necessária para a produção do biogás, a capacitação dos agricultores e o crescimento da geração e da distribuição de energia proveniente de biomassa.

Tramita na Assembleia Legislativa de Santa Catarina o Projeto de Lei (PL) 0097.4/2015, que institui o Programa Catarinense de Agroenergia, cujo objetivo é a produção de biogás oriundo de dejetos de suínos. Segundo o PL, o programa será desenvolvido em parceria com os criadores de suínos, agregados ou independentes, e com as secretarias de Agricultura e de Desenvolvimento Sustentável. As diretrizes dessa política serão definidas por meio de regulamentação específica.

São muitos os motivos que justificam a elaboração de uma política específica para a geração de bioenergia. A expectativa é a de que esse marco jurídico atenda às necessidades dos produtores rurais, proporcionando maior rentabilidade para a pequena propriedade por meio da geração de energia derivada da biomassa.

\section{Referências}

ANEEL - Agência Nacional de Energia Elétrica. Procedimentos e etapas do acesso para consumidor e distribuidora. Disponível em: $<\mathrm{http}: / /$ www.aneel.gov.br $>$. Acesso em: 18 abr. 2016.

Baron, S. Projeto Alto Uruguai: União de Produtores, universidades, Governo e Sociedade. Revista Brasileira de Bioenergia, 1, 9-11, 2012. Disponível em: http://143.107.4.241/ download/revista/RBB14.pdf.

Bavaresco, P. R. Ciclos Econômicos Regionais: modernização e empobrecimento. Chapecó: Argos, 2005.

Bley Jr., C.; Libânio, J. C.; Galinkin, M.; Oliveira, M. M. Agroenergia da biomassa residual: perspectivas energéticas. Socioambientais e ambientais. 2. ed. rev. Foz do Iguaçu: Techno Politik, 2009.

Brasil. Lei n. 12.651, de 25 de maio de 2012. Institui o Código Florestal Brasileiro. Brasília: DOU de 28.5.2012.

Brasil. Eletrosul. 2013. Disponível em: <http://www.eletrosul.gov.br/sala-de-imprensa/noticias/eletrosul-vai-instalar-usina-de-biogas-no-interior-de-santa-catarina $>$. Acesso em: 18 abr. 2016.

Brasil. Ministério do Meio Ambiente. Programa Nacional do Meio Ambiente II - PNMA II . Disponível em: http:// www.mma.gov.br/estruturas/pnma/_arquivos/pnma_ii2000_a_2004.pdf. Acesso em: 16 ago. 2015.

Brasil. Ministério de Minas e Energia. Programa de Incentivo às Fontes Alternativas de Energia Elétrica (Proinfa). Disponível em: $<$ http://www.mme.gov.br/programas/proinfa/>. Acesso em: 22 abr. 2015.

Brasil. Ministério de Minas e Energia. Empresa de Pesquisa Energética. Plano Decenal de Expansão de Energia 2024. 
Brasília, 2015.

Correa Lobato, R. O Sudoeste do Paraná antes da colonização. Revista Brasileira de Geografia, 32(1), 1970.

Dal Magro, J. et al. Relatório Alto Uruguai, Cidadania, Energia e Meio Ambiente - diagnóstico ambiental, social, econômico, estrutural e de gestão das propriedades rurais. Relatório Técnico. Eletrosul/Eletrobras, 2007. Disponível em: https://www.google.com.br/?gws_rd=ssl\#q=relat\%c3\%93rio+alto+uruguai,+cidadania, + energia + e+meio + . Acesso em 15 ago. 2015.

Dal Magro, M. L. P.; Renk, A.; Franco, G. M. de S. (Orgs.). Impactos socioambientais da implantação da hidroelétrica Foz do Chapecó. Chapecó: Argos, 2015.

Diário Catarinense. Reservas de água subterrânea estão sob risco de poluição no oeste catarinense. Florianópolis, 11 nov. 2013.

Esperancini, M. S. T.; Colen, F.; Bueno, O. de C.; Pimentel, A. E. B.; Simon, E. J. Viabilidade Técnica e Econômica da Substituição de Fontes Convencionais de Energia por Biogás em Assentamento Rural do Estado de São Paulo. Engenharia Agrícola, 7(1), 110-118, 2007. doi: 10.1590/ S0100-69162007000100004

Espíndola, C. J. As agroindústrias no Brasil: o caso Sadia. Chapecó: Grifos, 1999.

Granja São Roque. Quem somos. Disponível em: <http:// www.gsaoroque.com.br/br/quemsomos.html >. Acesso em: 18 abr. 2016.

Itaipu Binacional. Condomínio de Agroenergia para Agricultura Familiar começa a sair do papel. Jornal de Itaipu Eletrônico, 8 mar. 2010. Disponível em: $<$ http://jie.itaipu. gov.br/node/42718>. Acesso em: 18 abr. 2016.

Magalhães Santos, S. M. S. Lamento e dor. Uma análise sócio-antropológica do deslocamento compulsório provocado pela construção de barragens. Belém: UFPA, 2007.

Miele, M.; Waquil, P. D. Estrutura e dinâmica dos contratos na suinocultura de Santa Catarina: um estudo de casos múltiplos. Estudos Econômicos, 37(4), 817-847, 2007. doi: 10.1590/S0101-41612007000400005

Miranda, C. R. de; Palhares, J. C. P. Avaliação do termo de ajustamento de conduta da suinocultura AMAUC/Consórcio Lambari através de indicadores sociais, econômicos e ambientais. In: Coldebella, A.; Scheuermann, G. N. (Eds.). Relatório dos projetos concluídos 2010. Concórdia: Embrapa Suínos e Aves, 2011. p. 15-26.

Miranda, C. R. de; Silva, E. O. da; Bonez, G.; Palhares, J. C. P.; Suzin A. G. Gestão Ambiental na Suinocultura: a experiência do Termo de Ajustamento de Conduta (TAC) do Alto Uruguai Catarinense. In: Seminário de Gestão Ambiental na Agropecuária, 3., 2012, Bento Gonçalves. Anais... Bento Gonçalves: ProAmb, 2012.

Nações Unidas Convenção Quadro sobre Mudança Climática. Acordo de Paris, 2015. https://nacoesunidas.org/. Acesso em 15 de jun. de 2017.

Nogueira, L. A. Horta. Biodigestão: a alternativa energética. Rio de Janeiro: Nobel, 1986. Disponível em: $<$ http://www. ons.org.br/home>. Acesso em: 11 set. 2015.

Nogueira, L. A. Biodigestão: A alternativa energética. São Paulo: Nobel, 1992.

Plataforma Boas Práticas para o Desenvolvimento Sustentável. Condomínio Ajuricaba de Agroenergia para Agricultura Familiar, s/d. Disponível em: http://www.boaspraticas. org.br/index.php/pt/areas-tematicas/energias-renovaveis/ 16-condominio-ajuricaba-de-agroenergia-para-agricultura-familiar. Acesso em 16 ago. 2015.

Projeto Alto Uruguai. Disponível em: $<$ http://www.projetoaltouruguai.com.br $>$. Acesso em: 14 set. 2015.

Renk, A. A. A luta da erva - um ofício étnico da nação brasileira no oeste catarinense. 2. ed. Chapecó: Argos, 2006. v. 1, 250 p.

Rizzoni, L. B.; Tobias, A. C. T.; Del Bianchi, M.; Garcia, J. A. D. Biodigestão anaeróbia no tratamento de dejetos de suínos. Revista Científica Eletrônica de Medicina Veterinária. 18, 2012. Disponível em: http://faef.revista.inf.br/ imagens_arquivos/arquivos_destaque/W34ebZOEZuzvEvG_2013-6-28-18-12-37.pdf.

Santa Catarina. Decreto 24980/85. Dispõe sobre habitação urbana e rural. DOE 14 de março de 1985.

Santa Catarina. Instituto de Planejamento e Economia Agrícola - CEPA. Avaliação do Projeto Microbacias - 
nitoramento da Qualidade da Água. Florianópolis, 1999.

Testa, V. M.; Nadal, R.; Mior, L. C.; Baldissera, I. T.; Cortina, N. O desenvolvimento sustentável do oeste catarinense. Florianópolis: Epagri, 1996.a
Werlang, A. Disputas e ocupação no oeste catarinense: a atuação da Companhia Territorial Sul Brasil. Chapecó: Argos, 2006 